\title{
Application of Network and Multimedia Technology in University Physical Experiment Teaching
}

\author{
${ }^{\mathrm{a} C h e n g x u n ~ B e i, ~}{ }^{\mathrm{b}}$ Jianxin Peng* \\ ${ }^{a, b}$ Department of Physics, School of Science South China University of Technology Guangzhou, China
}

\begin{abstract}
University physical experiment is a compulsory basic course for the science and engineering students in the university. To activate students' enthusiasm in learning and make students master the basic methods and skills of physical experiment, the physical experiment teaching should comply with era development and establish a kind of innovative teaching system to cultivate creative students. This paper discusses the necessity and advantages of the teaching method by applying network and multimedia technology for the teaching of university physical experiment. This method would make full use of network and multimedia technology to activate the students' initiative and creativity in learning, enhance the students' efficiency in learning and boost the quality in physical experiment teaching.
\end{abstract}

Index Terms: network; multimedia; university physical experiment; teaching

(C) 2012 Published by MECS Publisher. Selection and/or peer review under responsibility of the International Conference on E-Business System and Education Technology

\section{Introduction}

In the university, the students must study some compulsory basic training courses on scientific experiment. University physical experiment is the first course for students to learn experimental method and skills after the students enter the university. It also exercises an invisible, formative influence on cultivating the good scientific quality and forming the scientific world view for students [1]. University physical experiment has the characteristics of a broad area, a boring principle and complicated operation. The traditional physical experimental teaching way is that teacher explains and demonstrates the experiment, the students operate experiment during the course, and the students copy with the experimental data and write a report after the course. If this type teaching way was used, the students might be felt that the physical experiment is boring and hard to understand [2]. On the other hand, university physical experiment teaching should activate students' enthusiasm in learning, make students master the basic knowledge, methods and skills of physical experiment by observing and analyzing the phenomenon of physical experiments and measuring the physical parameters.Moreover, it should also make students thoroughly understand the physical principles and train students' analysis and problem-solving abilities. So physical experiment teaching should comply with era 
development and establish a kind of innovative teaching system to cultivate creative people that possess of a solid basic knowledge. With the network and multimedia technology development, the application of network and multimedia technology provide a broad teaching space for the reform of experimental teaching methods and measures, the construction of new teaching mode and the improving of the quality of teaching [3]. Modern teaching means with network and multimedia technology can give full play to the subjective initiative of the students to solve problems and explore knowledge. It can also motivate students' the enthusiasm, initiative and creativity in learning.

\section{The necessity of applying the network and multimedia technology}

Generally speaking, the traditional mode of experimental teaching is, that students are expected to preview the principles and operation of experiment before class, and teacher instruct the principles of experiment and demonstrate the operation process of experiment, and then the students conduct the experiment themselves. In fact, the students' operating process is a repeat basically according to the teacher's demonstration. Obviously, there were lots of flaws in this type of teaching mode. Firstly, the previewing of students was confined to the book [1]. The experimental principles and experimental procedure were mechanically memorized. However, since the students have no perceptual knowledge about the experimental apparatus and experimental procedure, they did not really understand how to do the experiment. The previewing of students did not realize the desired teaching effect. Secondly, the teacher not only roughly explained the experimental principles, procedures, and points for attention according to the book, but also demonstrated the whole process of the experiment during the class. However, because of the limit of the space and experimental condition, there was a small visual range. Only few students could observe the operation process [1]. It was no doubt that there would be a bad influence on the quality of experiment teaching. Thirdly, some experimental instruments possess complexity structure. Although the teacher could clearly demonstrate their structure, principle and usage, the students wouldn't understand it immediately [1], especially in the wave display of oscilloscope, protean optical phenomenon and the interpretation in principles, Michelson interferometer and its' data readings accurately, and spectrometer adjustment, etc. Fourthly, because the university physical experiment and university physical theory were commenced at the same time and both two courses teaching were not synchronous, so it always came to the situation that students needed to perform experiment before they obtained the theoretical knowledge relevant to experiments. Moreover, there were no detail introductions on the experiment theory in book. If the relevant experimental theory knowledge could be learned in time, students only could finish the experiment mechanically and passively. This would restrict the students' initiative and creativity and could not cultivate the abilities to analyze and solve problems.

In view of the above problems, the teacher should made full use of the network and multimedia technology, and show the experimental teaching contents by a new teaching method that combined text, graphics, video, audio, animation as a whole via network and multimedia technology during the teaching course. The teacher also should made the best use of network resources to present the relevant teaching courseware about experimental principles, introduction of instruments, experimental procedures, instrumental joint, experimental phenomena on internet by using the techniques of the network and multimedia. These teaching coursewares could provide for students to preview before class and consult during class. Thus, the complex teaching problems would be simplified and the long or instant physical phenomena would be changed into the controllable and orderly process during the class. Moreover, physical phenomenon can be simulated vividly and physical law can be shown intuitively with the multimedia technology. This make the mechanical, boring, and force-feeding experiment teaching method become various forms, lively and interesting. The physical experimental teaching using the network and multimedia technology could use various senses to mobilize students' participation in teaching activities as effectively as possible, attract the attention of students, and inspire students' interest in learning. It also could help the teacher clearly explain experimental process and experimental method and greatly improve the students' learning in the depth and breadth. For example, in the experiment of the spectrometers use and the refractive index measurement for the triple prism, the spectrometer is a basic physical experimental instrument, but it is rather difficult to adjust for students because of operational multi-step and complexity. Moreover, the experimental phenomena of spectrometer couldn't be displayed visually. It is hard to realize a 
better teaching effect if only the teacher explained and demonstrated the experiment during the class [4]. However, applying the network and multimedia technology, the introductions and adjustment about the main component of spectrometer, the pictures and animations about the observed experimental phenomenon for every step could be presented on internet for students' previewing [5]. Thus, students could know the experiment results with visual image and understand the basic principles of spectrometer and the adjustment method before class. At the same time, teachers could use network and multimedia technology to illustrate the experimental operation and phenomenon, which would enhance the students to grasp the spectrometers structure and principle and make students fully understand the experimental contents and operational procedures. So the application of the network and multimedia technology could elevate students' practical ability and boost the ability that students use their theoretical knowledge to solve practical problems.

Concerning the asynchronization between theoretical teaching and experimental teaching, on the one hand, the teacher could present the experimental principle and relevant background knowledge by web page on the corresponding teaching website for students' learning. At the meantime, the teacher should take the characteristics of students' self-study into full consideration and provide some necessary hyperlinks for the experimental principle and its relevant knowledge on the web. When students met with the knowledge that they did not understand, they could click the corresponding link and enter directly webpage for further detail study. On the other hand, teacher could guide students how to use the internet to look up the knowledge that related to experimental principles, operation and phenomenon. The teacher should also ask some questions about the experiment principle. This kind of teaching method not only helped teachers explain the experiment during class, but also strengthened the teachers and students to interact. Furthermore, it would inspire the students' interest and enthusiasm in learning.

\section{Advantages of the network and multimedia technology for University Physical Experiment teaching}

In the traditional teaching of university physical experiment, the students lack full understanding and careful thinking for the experimental principle, procedures and skills. They often mechanically and passively finish the experiment according to the teacher's live explanation, demonstrations and guidance. This kind of teaching method could not adequately train students' ability to analyze and solve practical problems. Applying the network and multimedia technology in teaching can largely compensate for these shortcomings [6] and fully mobilize the students' independence and creativity in learning. The teaching method of applying of the network and multimedia technology in university physical experiment has more advantages than traditional one.

\section{1 Visuality}

Applying the network and multimedia technology in university physical experiment teaching can well embody the characteristics of visualization and rich visual effect of the interface. It not only aided teacher to explain and demonstrate experimental principle and phenomena, but also helped students to preview and review experiment principle and phenomena independent, and then aroused the students' interest and enthusiasm in learning university physical experiment. For example, in the experiments of demonstrating Michelson interferometer's adjustment and use, teacher could use digital cameras to take some pictures about instruments, data readings, experimental phenomena (Fig. 1) and then synthesize them into animation by animation software, then present them in teaching website directly for students' previewing by combining with the network and multimedia technology. During the class, the teacher can also explain the experiment using these animations further. Thus, the students' memory effects would be enhanced through multi-sensory stimulation. With visuality provided by the network and multimedia technology, the students can well master the university physical experiment that they had done. 


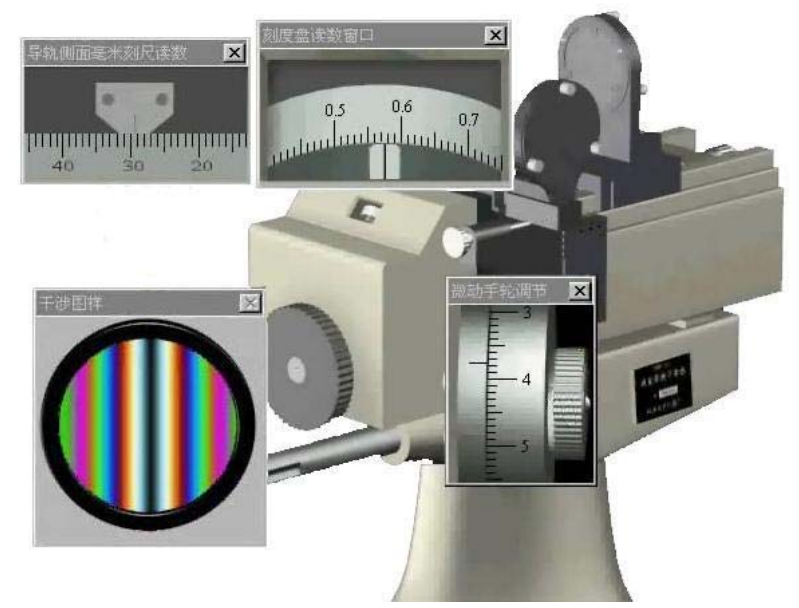

Figure 1. Michelson interferometer's data reading and observation of white light interference.

\section{2 High efficiency}

As mentioned above, the teacher could turn the original abstract into concrete and visualization by the network and multimedia technology in university physical experiment teaching. When the teachers presented the relevant teaching courseware about experimental principles, procedures, and phenomena as teaching coursewares before and during the class by using the network and multimedia technology, the students would grasp and understand university physical experimental principle, method, and process in a short time under multi-sensory stimulation. This could inspire the students' learning initiative and creativity, enhance the students' learning efficiency and boost the effect of university physical experiment teaching.

\section{3 Interactivity}

The teacher is the organizer and guider in the whole process of using the network and multimedia technology in university physical experimental teaching. The students' initiative and enthusiasm would be fully aroused by using situated learning environment [6]. The students' previewing and independent, teachers' guide and students' would provide a broad space for the teachers and students two-way communication. Furthermore, the students could feed back any difficult problems encountered in physical experiment to teachers and the teacher could know about the learning of students according to students' feedback and provide guidance in time through the use of EMAIL, BBS, Forum, QQ, MSN and so on. This teaching mode can strengthen teacher-student interaction between communication and feedback, improve teachers' teaching and students' studying, and consolidate the students' understanding and mastering of the experimental teaching contents.

\section{Conclusion}

With the development of network and multimedia technology, the university physical experiment teaching has entered a new era of modernization, which opened the senses of students in the forms of text, images, audio, animation, etc. It is beneficial to cultivate students' attention, imagination, observation, memory and thinking ability [7]. It is the responsibility that the times endowed to teacher that how to give full play to the advantage of network and multimedia technology teaching, how to promote physical experiment teaching reform and innovation and how to enhance the modernization level in university physical experiment teaching. It also put forward higher requirement for teachers. As a teacher, he should possess of more profound specialized knowledge, continuously improve teaching level himself, design more scientific and reasonable experimental 
course, and give full play to the advantage of network and multimedia technology in teaching. Applying the network and multimedia technology in university physical experiment teaching could increase the students' enthusiasm, initiative and creativity, deepen students' mastery of university physical experiment, enhance the students' learning efficiency and boost the quality of university physical experiment teaching.

\section{References}

[1] X. Ni, University Physical Experiment (in Chinese), Guangzhou: South China University of Technology Press, 2005.

[2] L. Wang, "Multimedia in University Physical Experiment (in Chinese)," China After School Education, No. 11 , pp:109, 2008.

[3] D. Jia, J. Zhang, F. Xiao, Z. Lu, "Optimization of University Physics Experiment Using Network Resources (in Chinese),” Journal of Hebei Medical University for Continuing Education, Vol . 21 ,No . 4, pp: 53-54, 2004.

[4] L. Yan, F. Hu, "On the Univer sity of Teaching Physics Experiment in the Application of Multimedia Technology (in Chinese),” Computer Knowledge And Technology, Vol.3,No.5, pp:985- 986,2008.

[5] http://202.38.220.14:8080/pe/shipincailiao.htm

[6] Z. Han, "Network teaching in college physicals experiment teaching (in Chinese)," China Electric Power Education, No.10, pp:151-152, 2009.

[7] B. Zhang, "Rational Use of the Multimedia in College Physics Experimental Teaching (in Chinese)," Jilin Agricultural, No.7, pp:238-239, 2010. 